\title{
Apresentação
}

\section{A teoria sociológica e os novos desafios para a pesquisa}

ELIDA RUBINI LIEDKE*

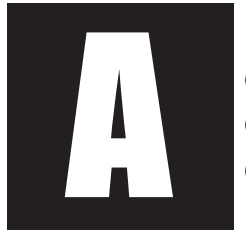

intensificação, nos últimos decênios, das relações de produção e de troca mercantil no plano mundial vem se fazendo acompanhar da redução - embora em graus diferenciados - da capacidade de controle dos estados nacionais sobre os problemas de ordenamento do trabalho e da produção de mercadorias em seus territórios. No processo de mundialização das relações sociais, a interação passa a deter novos significados, mediante as possibilidades de comunicação abertas pelos meios eletrônicos, acarretando a transformação das relações espaço-temporais, agora não mais definidas exclusivamente por referências convencionais, fundamentadas em princípios de continuidade de tempo e de territorialidade.

Na teoria sociológica, a problematização desse novo contexto histórico mundial vem dando lugar a um debate abrangente, no que respeita ao seu sentido e as suas implicações. Se a extensão da interação social ao plano mundial tem propiciado o convívio entre estilos de vida crescentemente diversificados, atualizando novas perspectivas de escolha pessoal, é sabido que raramente essas últimas têm sido facilitadas por uma desejável ampliação do acesso a bens, a serviços e ao conhecimento tecnicamente adequado. Ao contrário, assiste-se, hoje, à disseminação de práticas de segregação social em um sem número de recortes sociais (no trabalho, na política, entre regiões, de gênero, de etnia, e assim por diante).

* Professora do Programa de Pós-Graduação em Sociologia da Universidade Federal do Rio Grande do Sul, PhD. 
Poder-se-ia afirmar, em uma formulação sintética, que dois dilemas interconectados desafiam o debate atual acerca das alternativas possíveis face às divisões do mundo globalizado: ${ }^{1}$

(1) o alheamento defensivo, o auto-isolamento, vis a viso apelo à violência e (2) o enraizamento na tradição baseada em autoridade e hierarquia no cumprimento de normas pré-estabelecidas vis a vis o diálogo democrático face a demandas crescentes de participação social em espaços públicos.

Aceitando-se que conceitos e práticas de democracia social e politicamente extensiva requerem, dentre outros fatores, a mobilização da capacidade de entendimento, torna-se tarefa da teoria social a construção de cenários em ambientes de incerteza. Para isso se faz necessário considerar os limites e as perspectivas do jogo de forças sociais que interagem e se confrontam em estilos divergentes de avaliar e organizar a vida social, especialmente em condições de uso discricionário da informação, do conhecimento e da técnica e, ao mesmo tempo, buscar a construção de consensos baseados em escolhas justificadas ${ }^{2}$ (o quê? de quem? para quem?), em contraposição às formas de controle fundamentadas em lógicas reificadas acerca do mercado, da técnica e da burocratização política.

Em suma, coloca-se em foco a questão referente a de que modo a sociologia pode contribuir para o diálogo democrático, o qual, por sua vez, requer a negociação e a formulação de regras mais ou menos duradouras e implica em disponibilização de recursos facilitadores, ${ }^{3}$ amplamente acessíveis aos participantes.

Ao reunir a série de textos que compõem o presente dossiê da Revista Sociologias, buscou-se dar expressão ao espaço de discussão disponibilizado

1 GIDDENS, Anthony. A vida em uma sociedade pós-tradicional. In: GIDDENS, Anthony; Ulrich Beck e Scott Lash. Modernização reflexiva: Política, tradição, estética na ordem social moderna. São Paulo: UNESP, 1997; HABERMAS, Jurgen. A crise de legitimação do capitalismo tardio. Rio de Janeiro: Tempo Brasileiro/Tempo Universitário, 1980; ADORNO, Theodor W. e HORKHEIMER, Max, Dialética do esclarecimento. Rio de Janeiro: Jorge Zahar Editor, 1969.

2 GIDDENS, 1997, op. cit.; HABERMAS, Jurgen. "Discourse, Law and Sittlichkeit", in: DEWS, Peter, Autonomy and solidarity. London, N. York: Verso, 1992; HABERMAS, Jurgen. Teoria de la accion comunicativa: complementos y estudios previos. Ediciones Cátedra: Madrid, 1994.

3 LEVINE, Donald. Visões da tradição sociológica. Rio de Janeiro: Jorge Zahar Editor, 1997. 
no Programa de Pós-Graduação em Sociologia da Universidade Federal do Rio Grande do Sul, no decorrer do período entre setembro de 2002 e maio de 2003, para a realização do Workshop intitulado "Sociologia Contemporânea: teoria e método (desafios para a pesquisa)". Os seminários, em um total de 32 horas/aula, foram conduzidos pelos professores Renato Paulo Saul, da UNISINOS, Adrián Scribano, da Universidad Nacional de Villa María, Córdoba, Darío Rodriguez, da Universidad Católica de Chile, bem como pelos professores Bárbara Freitag e Carlos Benedito Martins, ambos da Universidade de Brasília.

Dando abertura à série de seminários iniciada em setembro de 2002, Renato Paulo Saul enfocou a obra de Anthony Giddens. Contribui, no presente dossiê, com o texto "Giddens: da ontologia social ao programa político, sem retorno", em que busca explicitar o sentido do programa político da terceira via, assim como da teoria social de Giddens. Também participante do referido Workshop, Adrián Scribano, em seu artigo "Reflexiones sobre una estrategia metodológica para el análisis de las protestas sociales", discute uma das possíveis estratégias de investigação dos assim chamados Cortes de Ruta, enquanto manifestações de movimentos sociais recentemente ocorridos na Argentina. No que se refere ao professor Darío Rodríguez, cuja participação ocorreu no terceiro módulo do Workshop, em que a obra de Luhmann foi enfocada, sua colaboração neste dossiê se expressa no seu artigo em co-autoria com Javier Torres Nafarrate, intitulado "Autopoiesis, la unidad de una diferencia: Luhmann y Maturana". Nesse artigo, os autores buscam explicitar o modo como Luhmann adaptou os conceitos da biologia de Humberto Maturana e o alcance que tem essa abordagem para a compreensão da sociedade globalizada moderna.

Além desses, outros estudiosos vieram a somar esforços para a abertura de novas perspectivas de realização de atividades acadêmicas e de cooperação inter-institucionais, no que respeita ao ensino e à pesquisa em teoria sociológica. Este é o caso de Peter Evans, da Universidade de Berkeley, Califórnia, em cujo artigo "Além da 'Monocultura Institucional': instituições, 
capacidades e o desenvolvimento deliberativo" enfoca o conceito de "virada institucional" na abordagem dos problemas do desenvolvimento. Contribuíram também para o presente dossiê Anne Marie Wautier, professora da UNIJUÍ, Miriam De Toni, socióloga da FEE, ambas doutorandas em Sociologia na UFRGS, e Enno D. Liedke Filho, professor do Programa de Pós-Graduação em Sociologia da UFRGS. Em "Para uma sociologia da experiência. Uma leitura contemporânea: François Dubet", Anne Marie Wautier propõe-se a divulgar a Sociologia da Experiência, teorizada pelo sociólogo francês François Dubet. Em "Visões sobre o trabalho em transformação", Miriam De Toni considera as implicações sociais do processo de reestruturação do capitalismo, especialmente no que respeita à ampliação da insegurança nas relações de trabalho e ao aprofundamento das desigualdades sociais. Finalmente, em "Sociologia Brasileira: tendências institucionais e epistemológico-teóricas contemporâneas", Enno D. Liedke Filho recupera lições da Sociologia da Sociologia e examina sete temas relevantes para a compreensão da evolução da sociologia na América Latina e no Brasil.

Importa ressaltar que as atividades do Workshop contaram também com o apoio institucional e financeiro da Pró-Reitoria de Pesquisa e do Instituto de Filosofia e Ciências Humanas da UFRGS.

$\mathrm{Na}$ busca de respostas aos questionamentos que desafiam a teoria sociológica hoje, os textos que seguem neste dossiê revelam um movimento permanente de elaboração analítico-crítica realizado pelos seus respectivos autores, expressando, cada um a sua maneira, a orientação de que a justificativa moral e intelectual das diferentes tradições da sociologia não se encontra tão-somente nos temas considerados e nos modelos de abordagem teórica adotados, como, por exemplo, a transformação do trabalho, ou a democracia na sociedade globalizada, analisados segundo a teoria dos sistemas sociais ou, alternativamente, segundo a análise de situações de interação social mas, de forma crucial, pela visão de mundo que constitui seus pontos de partida e pela abrangência do horizonte intelectual que essas abordagens aportam. 
Sociologias, Porto Alegre, ano 5, no 9, jan/jun 2003, p. 14-18

\section{Resumo}

O artigo apresenta os seis textos que integram o dossiê Teoria Sociológica, publicados neste número 9 da Revista Sociologias, do Programa de Pós-Graduação em Sociologia da UFRGS. Nesta apresentação busca-se salientar os desafios que se colocam, no contexto da globalização, à teoria sociológica orientada para a democracia.

Palavras-chave: globalização, teoria sociológica, democracia. 